\title{
Editorial:
}

\section{A novel formulation of Folic acid gel in the treatment of Desquamative Gingivitis}

\author{
Saif Khan ${ }^{1}$, Syed Ziaur Rahman ${ }^{2}$
}

Bangladesh Journal of Medical Science Vol. 19 No. 01 January'20. Page : 187-188 DOI: https://doi.org/10.3329/bjms.v19i2.44993

Periodontal disease is preceded by an inflammation in the gingiva surrounding the teeth called gingivitis ${ }^{1}$. Desquamative gingivitis (DG) is a nonplaque induced lesion of the gingiva and associated oral mucosa. It clinically presents as erythema, erosion and ulceration of the gingiva and oral mucosa. It is diagnosed by histopathological and immunofluorescencestudies. Though, most of the DG lesions are manifestations of oral lichen planus, pemphigoid, oralcandidiasis, local reaction to various oral hygiene product and dental materials, postmenopausal senile mucosal atrophy etc ${ }^{2}$. Topical steroids are thefirst line of drugs in the treatment of DG, however itis sometimes unresponsive or refractory making this condition annoying for both the patients and clinicians. Moreover, topical steroid use is alsoassociated with oral candidiasis, stomatopyrosis, hypogeusia, oral hairy leukoplakia andoral mucosalhypersensitivity ${ }^{3}$.

Folic acid (FA) is a water soluble vitamin which is not synthesized in the human body and works with vitamin B12 as a co-factor in various biological processes. FA is essential for protein synthesis and play important role in blood formation, mucosal health and prevention of neural tube defects. The normal serum folate levels range from 6 to $20 \mathrm{ng} / \mathrm{ml}$. The recommended daily dietary intake of FA is 400 microgram $^{4,5,6}$.

In oral cavity, FAis important in maturation and development of oral epithelial cells. It's deficiency results in abnormalities in rapidly proliferating epithelial cells like buccal and gingival cells ${ }^{7,8,9}$. Dreizen et al (1970) observed in their experimental study on marmosets that FAdeficiency caused various deficiency related changes within periodontium such as increased nuclear staining in basal cells and also degeneration and widening of intercellular spaces in spinous layer, interference in oral epithelium maturation, decreased keratinization and increased susceptibility to infection and oral ulceration ${ }^{10}$.

Vogel et al., (1976) in their double-blind study evaluated the effect of FAsupplementation (2mg tablet twice daily via oral route) on gingivitis in humans. They reported that FA supplementation increased the resistance of gingiva to local irritants and also reduced gingival inflammation which was reflected as decreased gingival exudates flow ${ }^{11}$. Vogel et al., (1978) further studied the efficacy of topical FA on gingival health in randomized controlled study using $1 \mathrm{mg} / \mathrm{ml}$ of FA solution as test group and placebo solution as control. The subjects were instructed to rinse with $5 \mathrm{ml}$ measure for 1 minute and spit-out and then rinse with water for 60 days. Subjects were evaluated for gingival health, plaque and bleeding indices after 60 days. There was significant difference in groups with respect to gingival and bleeding indices. It was concluded thatFA supplementation increases host resistance to gingival inflammation and ulceration ${ }^{12}$.Similarly,Pack (1984) in a randomized double study compared topical FA (5 ml of $1 \mathrm{mg}$ /

1. Saif Khan, Department of Periodontics and Community Dentistry, Dr.ZiauddinAhmad Dental College,Aligarh Muslim University, Aligarh 202002, India, Email: saifgood@gmail.com

2. Syed Ziaur Rahman, Department of Pharmacology, Jawaharlal Nehru Medical College, Aligarh Muslim University, Aligarh 202002,UP,India, Email: rahmansz@yahoo.com

Correspondence to: Syed Ziaur Rahman, Department of Pharmacology, Jawaharlal Nehru Medical College, Aligarh Muslim University, Aligarh 202002,UP,India, Email: rahmansz@yahoo.com 
$\mathrm{ml}$ Folate mouth rinse BD) and placebo mouth rinse with respect to colour change sites, bleeding sites and plaque scores. After 4 weeks folate mouthwash demonstrated significant reduction in gingival colour changes and bleeding sites as compared to placebo. Thus, showingthe beneficial effect of local FA on gingival health ${ }^{13}$.Interestingly, FA augments apoptosis of epithelial cells with damaged DNA by up regulating the $\mathrm{p} 53$ gene and down regulating Bcl-2 gene expression. This FA induced epithelial apoptotic mechanisms is critical for host defense and suppression of mutagenesis ${ }^{14}$.

Since, FA in local formulations has shown to augment angiogenesis, collagen deposition, re-epithelization and wound healing in skin in vivo models. Moreover, topical FA is associated with better dermal healing outcomes like enhanced skin firmness,collagen, procollagen levels and because of FA stability, nontoxicity, it has promising role in tissue engineering, wound healing and regenerative medicine ${ }^{15,16}$. In the light of above studies, we propose an innovative use of local FA gel in the treatment of oral ulcer and DG lesions and formulated a gel $(100 \mathrm{ml}$ of $0.1 \%)$ with following constituents: Carbopal $934 \mathrm{CDH}$ (0.5 gm), Polyethylene glycol $200(15 \mathrm{ml})$, Glycerine $(5 \mathrm{ml})$, Methyl Paraben (0.18 gm),Propylparaben (0.02 gm), Aspartame (0.4gm), FA (0.1 gm) and Distill water (78.8 $\mathrm{ml})$.This novel gel is tested in animal model for oral ulcer and found very promising results.

\section{References:}

1. Kasuma, N., Arma, U., Risalina, L., Liputo, I., \&Fajrin, F. (2019). $\mathrm{Zn}$ as the Factor of Alkaline Phosphatase in Periodontal Patients consuming Minangkabau food in West Sumatra, Indonesia. Bangladesh Journal of Medical Science, 18(2), 228-232

2. Glickman I, Smulow JB. Chronic Desquamative Gingivitis-Its Nature and Treatment. J Periodontol 1964; 35(5):397-405.

3. M.A. González-Moles and C. Scully. Vesiculo-erosive Oral Mucosal Disease-Management

with Topical Corticosteroids: (2) Protocols, Monitoring of Effects and Adverse Reactions, and the Future. $J$ Dent Res 2005; 84:302-308.

4. Taruscio D, Carbone P, Granata O, Baldi F, Mantovani. A Folic acid and primary prevention of birth defects. Biofactors 2011; 37: 280-4.

5. Lewis DP, Van Dyke DC, Willhite LA, Stumbo PJ, Berg MJ. Phenytoin-Folic Acid Interactions. Ann Pharmacother 1995; 28: 726-35.

6. Hussein H, Brown RS (2015) What is the Effect of Folic Acid Supplementation on the Incidence or Reduction of Phenytoin-Induced Gingival Overgrowth? A Systematic Review. Int $j$ Dent Oral Health 2015; 1(5) http://dx.doi. org/10.16966/2378-7090.

7. Hermos, J. A., Adams, W., Liu, Y., Sullivan, L., and Trier, J.: Mucosa of the small intestine in folate deficient alcoholics. Ann Intern Med 1972; 76: 957.

8. Whitehead, N., Reyner, F., and Lindenbaum, J.: Megaloblastic changes in the cervical epithelium. $J \mathrm{Am}$ Med Assoc 1973; 226: 1421.
9. Van Niekerk, W. A.: Cervical cytological abnormalities caused by folic acid deficiency. Acta Cytol (Baltimore) 1966; 10: 67 .

10. Dreizen S, Levy BM, Bernick S. Studies on the biology of the periodontium of marmosets: The effect of folic acid deficiency on marmoset oral mucosa. J Dent Res 1970; 49: 616-620.

11. Vogel R I, Fink R A, L C Schneider, Oscar Frank, Herman Baker. The Effect of Folic Acid on Gingival Health. J Periodontol 1976;11:667-668.

12. Vogel RI, Fink RA, Frank O, Baker H. The effect of topical application of folic acid on gingival health. $J$ Oral Med 1978; 33: 20-22.

13. Pack ARC (1984) Folate mouthwash: effects on established gingivitis in periodontal patients. J Clin Periodontol1984; 11: 619-628.

14. Cao DZ, Sun WH, Ou XL, Yu Q, Yu T, Zhang YZ, Wu ZY, Xue QP, Cheng YL. Effects of folic acid on epithelial apoptosis and expression of Bcl-2 and p53 in premalignant gastric lesions. World J Gastroenterol. 2005; 11(11):1571-6.

15. Duman, N.; Duman, R.; Tosun, M.; Akıc1, M.; Göksel, E.; Gökçe, B.; Alagöz, O. Topical folinic acid enhances wound healing in rat model. Adv. Med. Sci. 2018; 63: 347-352.

16. Fernández-Villa D, Jiménez Gómez-Lavín M, Abradelo C, San Román J, Rojo L.Tissue Engineering Therapies Based on Folic Acid and Other Vitamin B Derivatives. Functional Mechanisms and Current Applications in Regenerative Medicine. Int J Mol Sci. 2018; 19(12). pii: E4068. doi: 10.3390/ijms19124068. 